\title{
Clinical characteristics and risk factors for death in patients with stress cardiomyopathy in the ICU
}

\author{
Tiezhu Yao ${ }^{1}$, Yuhong Chen ${ }^{2}$, Jingtao $\mathrm{Ma}^{1}$, Zhenjie $\mathrm{Hu}^{2}$ \\ ${ }^{1}$ Department of Cardiology, The Fourth Hospital of Hebei Medical University, Shijiazhuang, China; ${ }^{2}$ Department of Critical Care Medicine, The \\ Fourth Hospital of Hebei Medical University, Hebei Key Laboratory of Critical Disease Mechanism and Intervention, Shijiazhuang, China \\ Contributions: (I) Conception and design: Z Hu, T Yao; (II) Administrative support: Z Hu, J Ma; (III) Provision of study materials or patients: Y Chen; \\ (IV) Collection and assembly of data: T Yao; (V) Data analysis and interpretation: T Yao, Y Chen; (VI) Manuscript writing: All authors; (VII) Final \\ approval of manuscript: All authors. \\ Correspondence to: Zhenjie Hu. Department of Critical Care Medicine, The Fourth Hospital of Hebei Medical University, Hebei Key Laboratory of \\ Critical Disease Mechanism and Intervention, 12 Jiankang Road, Shijiazhuang 050017, China. Email: syicuhzj@163.com.
}

Background: This study aimed to investigate the clinical manifestations and risk factors for 28-day mortality in patients with stress cardiomyopathy (SC) in the intensive care unit (ICU).

Methods: This retrospective study was carried out from April 2015 to March 2021. Fifty-five patients in the ICU were diagnosed with SC. Two patients were excluded due to a history of atrial fibrillation (AF), and 53 patients were enrolled in the study. Baseline demographics and clinical characteristics were collected, and the 28-day mortality rate was calculated. Multivariate and univariate logistic regression analyses were used to determine the significant predictors of 28-day mortality.

Results: Of the 53 patients, almost half (47.17\%) were male. The most common stress trigger was sepsis (37.74\%). Due to sedation and tracheal intubation, $49.06 \%$ of SC patients were unable to express their symptoms, and only $3.77 \%$ of patients presented with chest pain. The proportion of patients with complications of systolic heart failure and cardiogenic shock was $77.36 \%$ and $39.62 \%$, respectively. The mean Acute Physiology and Chronic Health Evaluation (APACHE) II score when patients were admitted into the ICU was 21.17 \pm 8.41 , and the Sequential Organ Failure Assessment (SOFA) score at diagnosis of SC was $9.30 \pm 4.56$. Eighteen (33.96\%) SC patients had new-onset AF while in the ICU. The 28-day mortality rate in patients with SC in the ICU was $64.15 \%$. Univariate analysis found that 5 variables [SOFA score at diagnosis of SC, estimated glomerular filtration rate (eGFR) $<60 \mathrm{~mL} / \mathrm{min}$ at diagnosis of SC, maximum norepinephrine dose, new-onset $\mathrm{AF}$, and systolic heart failure] were correlated with 28-day mortality in patients with SC in the ICU. Multivariate logistic regression analysis suggested SOFA score at diagnosis of SC $(\mathrm{P}=0.042)$, eGFR $<60 \mathrm{~mL} / \mathrm{min}$ at diagnosis of $\mathrm{SC}(\mathrm{P}=0.027)$, and new-onset $\mathrm{AF}(\mathrm{P}=0.043)$ as independent predictors of 28-day mortality.

Conclusions: Male patients with SC were relatively more common in the ICU than in the cardiology unit. Sepsis was a common stress trigger. The 28-day mortality rate was very high. The SOFA score and eGFR $<60 \mathrm{~mL} / \mathrm{min}$ at diagnosis of SC and new-onset AF may have influenced patients' short-term prognosis.

Keywords: Stress-induced cardiomyopathy; takotsubo cardiomyopathy; apical ballooning syndrome; intensive care unit; retrospective study

Submitted Oct 14, 2021. Accepted for publication Nov 25, 2021.

doi: $10.21037 / \mathrm{apm}-21-3223$

View this article at: https://dx.doi.org/10.21037/apm-21-3223 


\section{Introduction}

Stress cardiomyopathy (SC), also referred to as 'takotsubo syndrome' or 'apical ballooning syndrome', was first described in 1990. As reflected in its Japanese name 'takotsubo', the left ventricle (LV) has an octopus traplike appearance at end systole in acute attacks (1). This condition is characterized by transient diastolic and systolic $\mathrm{LV}$ dysfunction, with various wall-motion abnormalities. SC usually occurs after physical or psychological stress and predominantly affects postmenopausal women, although in several registries and case series, up to $10 \%$ of SC patients are male $(2,3)$.

The pathophysiology of SC is complex and not fully understood. Through enhanced adrenergic stimulation and excess catecholamine concentration, inflammatory, genetic, neuroendocrine, and metabolic factors may participate in the pathogenesis of the reversible myocardial stunning related to SC (3-5). Patients in the intensive care unit (ICU) have multiple critical illnesses causing severe stress, including respiratory hypoxia, hypercapnic respiratory failure, sepsis, coma, and shock, and thus they have a high risk of SC. Several mechanisms or aetiologies may explain the occurrence of SC in ICU and are may be combined: catecholamine toxicity, psychological stress, neurological impairment, ischemia and left ventricular outflow track obstruction (6). Previous studies have reported that SC incidence in the ICU ranged from $1.5 \%$ to $5.6 \%(6-8)$. One study showed that $>20 \%$ of patients admitted to the ICU displayed SC-like LV apical ballooning (9). The initial diagnosis of SC is challenging, especially for ICU patients as they are given sedation or intubation and thus are unable to complain of their symptoms. Identifying specific clinical features might contribute to the screening of SC in the ICU. Hence, we conducted a retrospective investigation of the clinical features and outcomes of SC patients in need of intensive care therapy at a university-affiliated hospital in China. We present the following article in accordance with the STROBE reporting checklist (available at https:// dx.doi.org/10.21037/apm-21-3223).

\section{Methods}

\section{Ethical approval and consent}

All procedures performed in this study involving human participants were in accordance with the Declaration of Helsinki (as revised in 2013). The study was approved by Ethics Committee of The Fourth Hospital of Hebei
Medical University (No. 2021KS045). Individual consent for this retrospective analysis was waived.

\section{Design and setting}

This retrospective observational study involved 55 patients with SC in a general ICU at The Fourth Hospital of Hebei Medical University from April 2015 to March 2021. We defined SC in accordance with the International Takotsubo (InterTAK) Diagnostic Criteria (10) (Table 1). The criteria for exclusion were: (I) age $<18$ years, (II) previous medical history of atrial fibrillation (AF), and (III) lack of fulfilment of the InterTAK Diagnostic Criteria. After excluding 2 patients on the basis of the above criteria, 53 patients were included in the study (Figure 1). The patients were divided into 2 groups: the survival group and nonsurvival group. Clinical characteristics of the patients were collected. A comparison of the clinical features, electrocardiogram (ECG), transthoracic echocardiography (TTE), and laboratory data in the survival group $(\mathrm{n}=19)$ and nonsurvival group $(n=34)$ was carried out. The research was conducted in accordance with the principles outlined in the Declaration of Helsinki.

\section{Data collection}

We collected demographic parameters such as age, sex, body mass index, stress triggers, medical history, symptoms, and drugs on admission. The Acute Physiology and Chronic Health Evaluation (APACHE) II score at admission to the ICU and Sequential Organ Failure Assessment (SOFA) score at diagnosis of SC were documented. Diastolic blood pressure (DBP), heart rate (HR), systolic blood pressure (SBP), ECG, TTE, hemoglobin, lactic acid, and serum creatinine were detected and documented at diagnosis of SC. In addition, the estimated glomerular filtration rate (eGFR) was determined using the isotope dilution mass spectrometry (IDMS)-traceable Modification of Diet in Renal Disease equation (IDMS-MDRD) (11). Peak creatine kinase-MB, peak troponin-I, peak brain natriuretic peptide, acute heart failure complications, ICU interventions, and clinical outcomes were also collected. The TTEs and ECGs were independently reviewed by an experienced intensivist and an experienced cardiologist to reaffirm the diagnosis of SC.

\section{Statistical analyses}

SPSS version 23 (IBM Corp., Armonk, NY, USA) was 
Table 1 InterTAK diagnostic criteria cited from International Expert Consensus Document on Takotsubo Syndrome (Part I): Clinical Characteristics, Diagnostic Criteria, and Pathophysiology

1. Patients show transient left ventricular dysfunction (hypokinesia, akinesia, or dyskinesia) presenting as apical ballooning or midventricular, basal, or focal wall motion abnormalities. Right ventricular involvement can be present. In addition to these regional wall motion patterns, transitions between all types can exist. The regional wall motion abnormality usually extends beyond a single epicardial vascular distribution; however, rare cases can exist where the regional wall motion abnormality is present in the subtended myocardial territory of a single coronary artery (focal TTS)

2. An emotional, physical, or combined trigger can precede the takotsubo syndrome event, but this is not obligatory

3. Neurologic disorders (e.g., subarachnoid haemorrhage, stroke/transient ischaemic attack, or seizures) as well as pheochromocytoma may serve as triggers for takotsubo syndrome

4. New ECG abnormalities are present (ST-segment elevation, ST-segment depression, T-wave inversion, and QTc prolongation); however, rare cases exist without any ECG changes

5. Levels of cardiac biomarkers (troponin and creatine kinase) are moderately elevated in most cases; significant elevation of brain natriuretic peptide is common

6. Significant coronary artery disease is not a contradiction in takotsubo syndrome

7. Patients have no evidence of infectious myocarditis

8. Postmenopausal women are predominantly affected

Website link: https://academic.oup.com/eurheartj/article/39/22/2032/5025412. InterTAK, International Takotsubo; ECG, electrocardiogram.

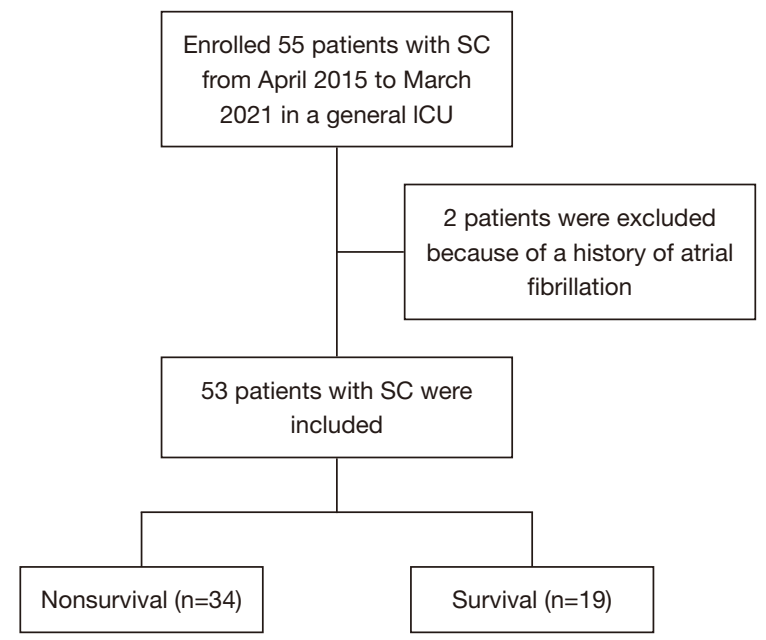

Figure 1 Study flow chart. SC, stress cardiomyopathy.

used for statistical analyses. Data are expressed as average value \pm standard deviation or median (interquartile range) for continuous data with normal distribution or nonnormal distribution, respectively. Frequency (\%) was used for categorical data. The Kolmogorov-Smirnov test was applied to evaluate the normality of the distribution. The Mann-Whitney U-test and Student's $t$-test were utilized to compare continuous data with non-normal and normal distributions, respectively. The $\chi^{2}$ or Fisher exact test was applied to compare categorical data between different groups. Mean imputation was performed for mean values of missing variables. Logistic regression models were used to identify multivariate and univariate risk factors for 28-day mortality in SC patients. The variables with significant difference in univariate analysis were included in the multivariate model. All statistical tests were 2-sided. $\mathrm{P}<0.05$ was regarded as statistically significant.

\section{Results}

Fifty-five patients with SC participated in this retrospective observational study. Two patients were excluded due to a history of $\mathrm{AF}$, and the remaining 53 patients were included in the study (Figure 1). The mean age of the participants was $70.70 \pm 12.13$ years (range, 33-89 years). Almost half (47.17\%) of the participants were male, and the mean body mass index (BMI) was $23.01 \pm 3.43\left(\mathrm{~kg} / \mathrm{m}^{2}\right)$. The majority of patients had clear stress triggers, including physical (88.68\%) and emotional (7.55\%) triggers. The most common physical stress trigger was sepsis $(37.74 \%)$, followed by operative procedure $(28.30 \%)$, comatose state $(11.32 \%)$, and cancer pain $(3.77 \%)$. The other physical triggers $(7.55 \%)$ included ventricular tachycardia, cardiac arrest, hemoptysis, and hematemesis. The patients' previous medical histories included malignancy (69.81\%), hypertension (41.50\%), diabetes $(26.42 \%)$, coronary heart disease $(16.98 \%)$, prior stroke $(15.09 \%)$, chronic obstructive pulmonary disease 
Table 2 Clinical features of the study population

\begin{tabular}{|c|c|}
\hline Variables & Mean $(n=53)$ \\
\hline \multicolumn{2}{|l|}{ Demographic data } \\
\hline Age (year) & $70.70 \pm 12.13$ \\
\hline Male (\%) & $28(47.17)$ \\
\hline Body mass index $\left(\mathrm{kg} / \mathrm{m}^{2}\right)$ & $23.01 \pm 3.43$ \\
\hline \multicolumn{2}{|l|}{ Stress triggers (\%) } \\
\hline None & $2(3.77)$ \\
\hline Emotional & $4(7.55)$ \\
\hline Physical & $47(88.68)$ \\
\hline Sepsis & $20(37.74)$ \\
\hline Operative procedure & $15(28.30)$ \\
\hline Comatose state & $6(11.32)$ \\
\hline Cancer pain & $2(3.77)$ \\
\hline Other & $4(7.55)$ \\
\hline \multicolumn{2}{|l|}{ Medical history (\%) } \\
\hline Malignancy & $37(69.81)$ \\
\hline Hypertension & $22(41.50)$ \\
\hline Diabetes & $14(26.42)$ \\
\hline Coronary heart disease & $9(16.98)$ \\
\hline Prior stroke & $8(15.09)$ \\
\hline Chronic obstructive pulmonary disease & $2(3.77)$ \\
\hline Hyperlipidemia & $1(1.89)$ \\
\hline Epilepsy & $1(1.89)$ \\
\hline \multicolumn{2}{|l|}{ Symptoms (\%) } \\
\hline Inability to express symptoms & $26(49.06)$ \\
\hline Dyspnea & $18(33.96)$ \\
\hline Chest pain & $2(3.77)$ \\
\hline \multicolumn{2}{|l|}{ Drugs on admission (\%) } \\
\hline CCB & $11(20.75)$ \\
\hline Antiplatelet drugs & $8(15.09)$ \\
\hline Diuretics & $6(11.32)$ \\
\hline ACEI/ARB & $5(9.43)$ \\
\hline Beta-blocker & $2(3.77)$ \\
\hline \multicolumn{2}{|l|}{ Acute heart failure complications (\%) } \\
\hline Acute respiratory failure & $42(79.25)$ \\
\hline Systolic heart failure & $41(77.36)$ \\
\hline Cardiogenic shock & $21(39.62)$ \\
\hline
\end{tabular}

Table 2 (continued)
Table 2 (continued)

\begin{tabular}{lc}
\hline Variables & Mean $(\mathrm{n}=53)$ \\
\hline ICU interventions (\%) & $47(88.70)$ \\
Use of norepinephrine & $41(77.36)$ \\
Use of brain natriuretic peptide & $27(50.94)$ \\
Use of levosimendan & $42(79.25)$ \\
Invasive mechanical ventilation & $18(33.96)$ \\
CRRT & $2(3.77)$ \\
IABP insertion & \\
During ICU stay & $21.17 \pm 8.41$ \\
APACHE II score (admission to ICU) & $9.30 \pm 4.56$ \\
SOFA score (at diagnosis of SC) & $34(64.15)$ \\
Clinical outcomes & \\
28-day mortality (\%)
\end{tabular}

CCB, calcium channel blockers; ACEI, angiotensin-converting enzyme inhibitors; $A R B$, angiotensin receptor blocker; CRRT, renal replacement therapy; IABP, intra-aortic balloon counterpulsation; APACHE II, Acute Physiology and Chronic Health Evaluation II; SOFA, sequential organ failure assessment.

(3.77\%), hyperlipidemia (1.89\%), and epilepsy (1.89\%). Due to sedation and tracheal intubation, $49.06 \%$ of SC patients in the ICU were unable to express their symptoms, $33.96 \%$ of patients had dyspnea, and only $3.77 \%$ of patients presented with chest pain. The most common acute heart failure complication was acute respiratory failure (79.25\%), followed by systolic heart failure (77.36\%), and cardiogenic shock (39.62\%). Eighteen (33.96\%) patients had new-onset AF. During intensive care treatment, $86.79 \%$ of patients used norepinephrine, $77.36 \%$ brain natriuretic peptide, and $50.94 \%$ levosimendan. In some cases, support techniques were also used: $79.25 \%$ of patients required mechanical ventilation, $33.96 \%$ were on continuous renal replacement therapy (CRRT), and $3.77 \%$ were implanted with an intraaortic balloon pump (IABP). The mean APACHE II score upon admission to the ICU was $21.17 \pm 8.41$, and the mean SOFA score at diagnosis of SC was $9.30 \pm 4.56$. The 28-day mortality rate in SC patients in the ICU was $64.15 \%$ (Table 2).

SC patients in the ICU were assigned to 2 groups: the survival group and nonsurvival group. A comparison of the clinical features, ECG, TTE, and laboratory data of the survival $(n=19)$ and nonsurvival groups $(n=34)$ is shown in Tables 3,4. No significant difference was observed between the groups in sex ratio, age, medical history, symptoms, or 
Table 3 Comparison of clinical characteristics between survival and nonsurvival groups

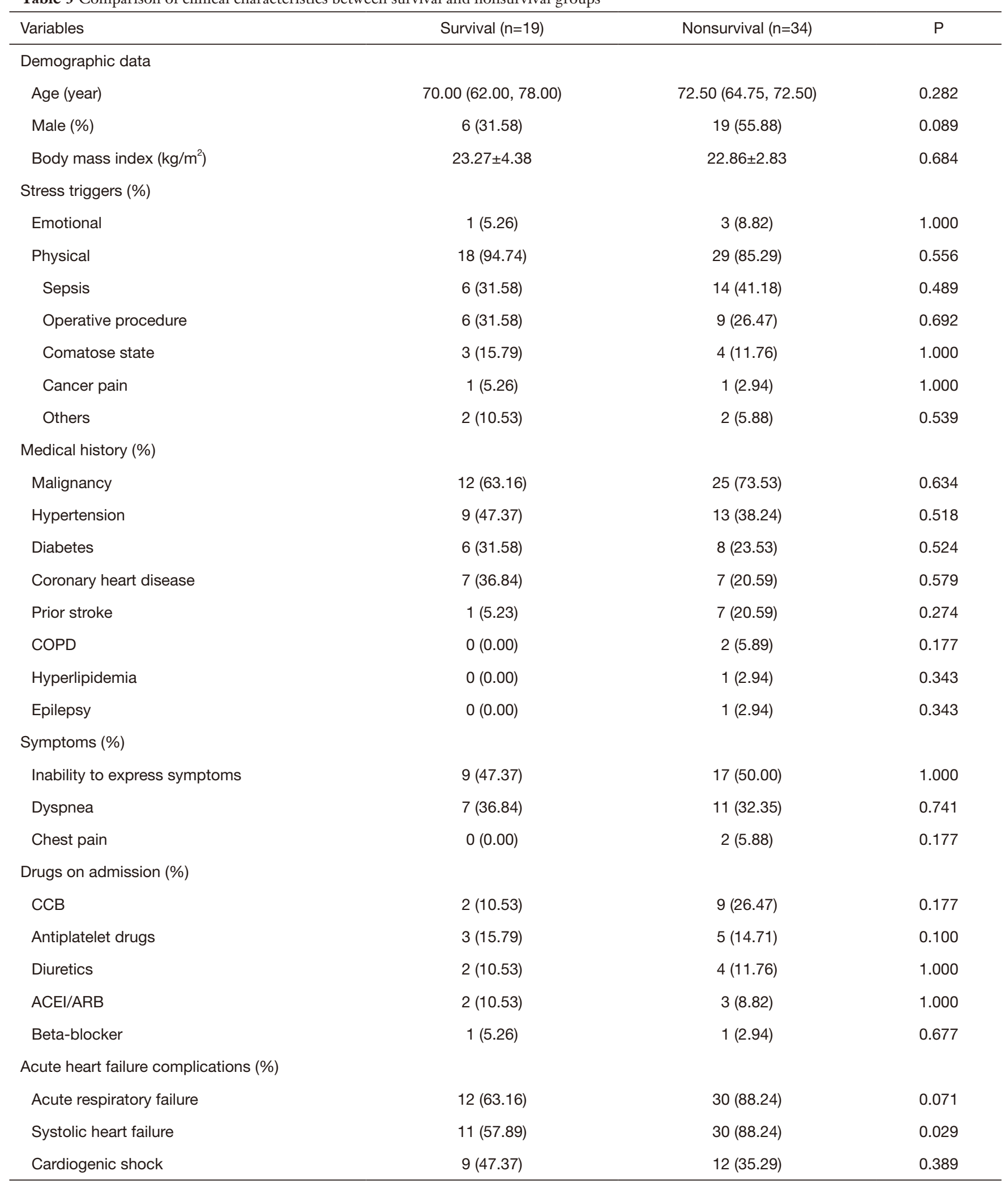

Table 3 (continued) 
Table 3 (continued)

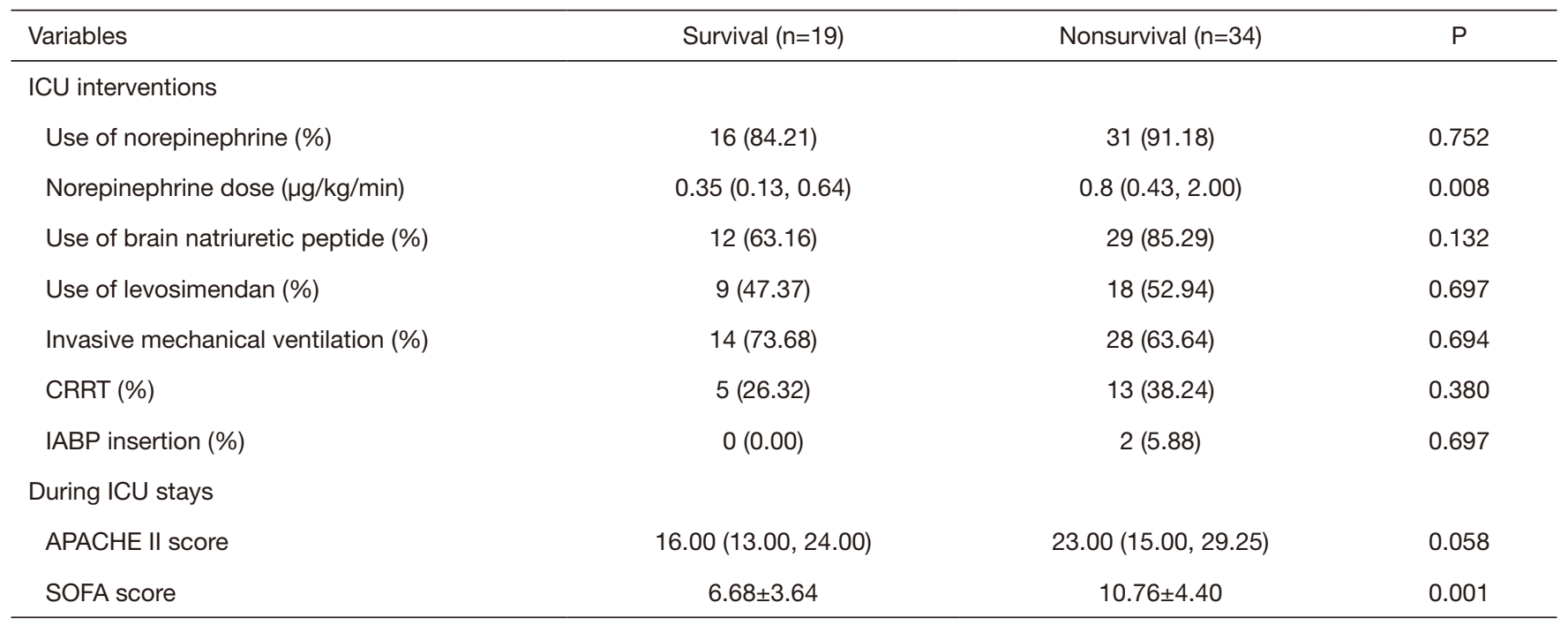

COPD, chronic obstructive pulmonary disease; CCB, calcium channel blockers; ACEl, angiotensin-converting enzyme inhibitors; ARB, angiotensin receptor blocker; ICU, intensive care unit; CRRT, renal replacement therapy; IABP, intra-aortic balloon counterpulsation; APACHE II, Acute Physiology and Chronic Health Evaluation II; SOFA, sequential organ failure assessment.

drugs on admission. Participants in the nonsurvival group showed a higher prevalence of systolic heart failure $(88.24 \%$ vs. $57.89 \%, \mathrm{P}=0.029)$ than those in the survival group. The maximum norepinephrine dose $[0.8(0.43,2.00)$ vs. 0.35 $(0.13,0.64), \mathrm{P}=0.008]$ and the SOFA score $(10.76 \pm 4.40$ vs. $6.68 \pm 3.64, \mathrm{P}=0.001)$ at diagnosis of $\mathrm{SC}$ were higher in the nonsurvival group. Although there was no significant difference in APACHE II score between the groups [23.00 $(15.00,29.25)$ vs. 16.00 (13.00, 24.00), $\mathrm{P}=0.058]$, the nonsurvival group had an increasing trend (Table 3). No significant difference was observed between the groups in SBP, DBP, or HR at diagnosis of SC. New-onset AF (47.06\% vs. $10.53 \%, \mathrm{P}=0.007$ ) was more frequent in the patients who died, but there was no significant difference between the 2 groups in other ECG changes, such as ST elevation, ST depression, inverted T-waves, and left bundle branch block $(\mathrm{P}>0.05)$. As shown by the TTE results, compensatory hyperkinesia in the basal segments and a typical pattern of apical ballooning with akinesia in the apical LV segments were observed in most patients $(n=50)$. The results also revealed obviously reduced $L V$ ejection fraction in the survival and nonsurvival groups $(37.7 \% \pm 10.97 \%$ and $33.68 \% \pm 7.24 \%$, respectively), and the nonsurvival group had a decreasing trend. Although there was no significant difference between the groups in peak values of troponin-I, creatine kinase- $M B$, and brain natriuretic peptide $(\mathrm{P}=0.111)$, the nonsurvival group showed an increasing trend. Patients in the nonsurvival group showed a higher prevalence of eGFR $<60 \mathrm{~mL} / \mathrm{min}(70.56 \%$ vs. $36.84 \%, \mathrm{P}=0.017)$ than those in the survival group.

Univariate analysis found that 5 variables (SOFA score at diagnosis of SC, eGFR $<60 \mathrm{~mL} / \mathrm{min}$ at diagnosis of $\mathrm{SC}$, maximum norepinephrine dose, new-onset $\mathrm{AF}$, and systolic heart failure) were correlated with 28-day mortality in SC patients in the ICU. Multivariate analysis showed that the risk factors for 28-day mortality in SC patients in the ICU were SOFA score at diagnosis of SC [odds ratio (OR), 1.262; $95 \%$ confidence interval (CI): 1.008-1.580; $\mathrm{P}=0.042$ ], eGFR $<60 \mathrm{~mL} / \mathrm{min}$ at diagnosis of SC (OR, 6.049; $95 \%$ CI: 1.224-29.897; $\mathrm{P}=0.027$ ), and new-onset $\mathrm{AF}$ (OR, 7.789; 95\% CI: 1.063-57.088, $\mathrm{P}=0.043$ ) (Table 5).

\section{Discussion}

In this retrospective study, the clinical manifestations of patients with SC in the ICU were investigated, and the risk factors that influenced 28-day mortality were evaluated. In our study, nearly half of the participants were men. At $88.68 \%$, patients with physical triggers were far more common than those with emotional triggers. Only $3.77 \%$ of patients presented with chest pain. The proportion of patients in our study with complications of systolic heart failure and cardiogenic shock, was $77.36 \%$ and $39.62 \%$, respectively. A total of $86.79 \%$ of patients were given 
Table 4 Comparison of clinical parameters, ECG, echocardiography and laboratory data between survival and nonsurvival

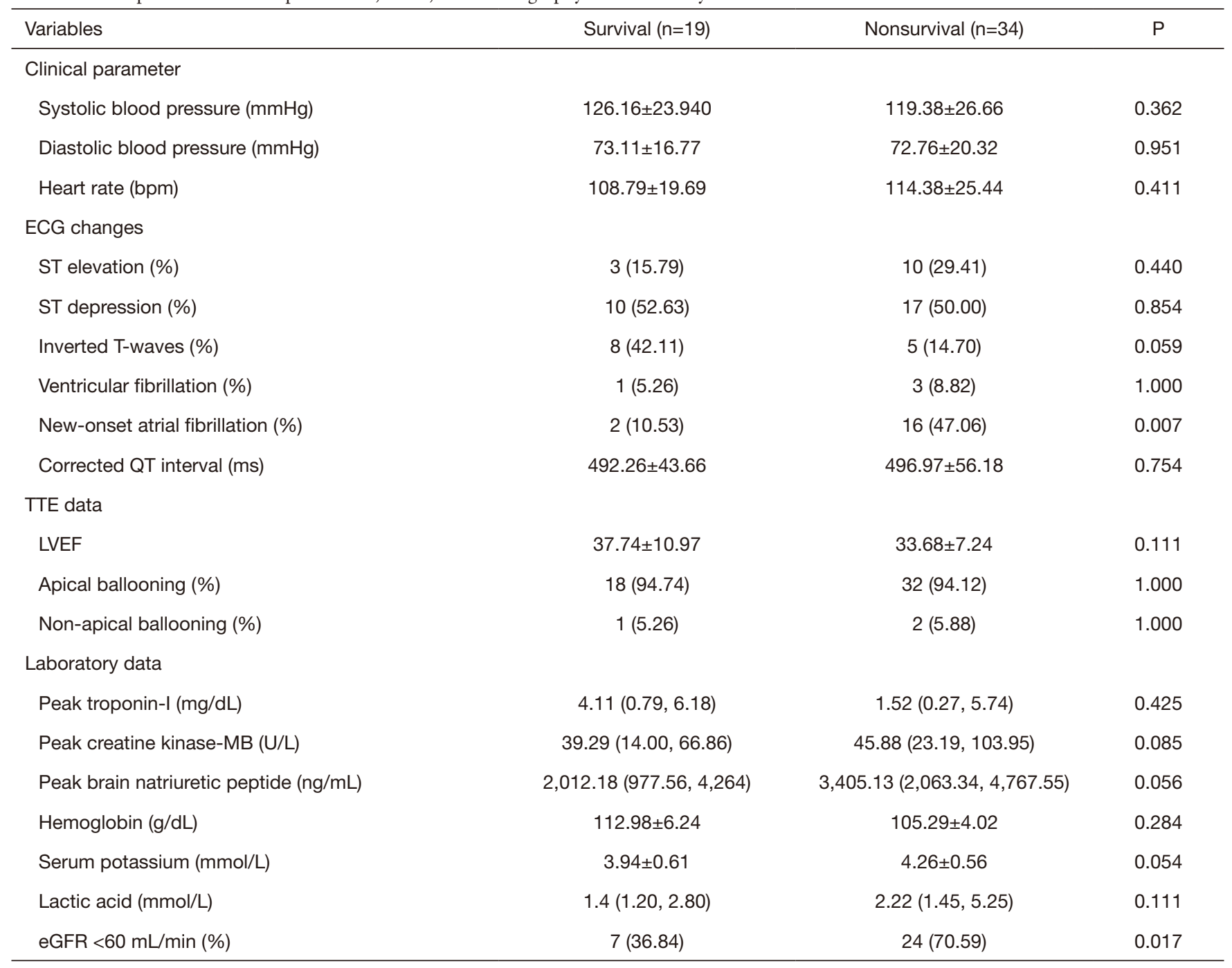

ECG, electrocardiogram; TTE, transthoracic echocardiography; SC, stress cardiomyopathy; LVEF, left ventricle ejection fraction; eGFR, estimated glomerular filtration rate.

Table 5 Multivariate analysis of 28-day mortality of patients with stress cardiomyopathy in the ICU

\begin{tabular}{lccc}
\hline Variables & OR & $95 \% \mathrm{Cl}$ \\
\hline SOFA score at diagnosis of SC & 1.262 & $1.008-1.580$ & 0.042 \\
eGFR $<60 \mathrm{~mL} /$ min at diagnosis of SC & 6.049 & $1.224-29.897$ & 0.027 \\
Norepinephrine dose at diagnosis of SC & 1.504 & $0.494-4.578$ \\
New-onset atrial fibrillation & 7.789 & $1.063-57.088$ & 0.473 \\
Systolic heart failure & 5.188 & $0.857-31.420$ & 0.073 \\
\hline
\end{tabular}

SOFA, sequential organ failure assessment; SC, stress cardiomyopathy; eGFR: estimated glomerular filtration rate. 
norepinephrine, and $79.25 \%$ of patients needed invasive mechanical ventilation. The 28 -day mortality rate of patients with SC in the ICU was $64.15 \%$. The independent risk factors of 28-day mortality in patients who had SC in the ICU were SOFA score at SC diagnosis, eGFR $<60 \mathrm{~mL} / \mathrm{min}$ at diagnosis of SC, and new-onset $\mathrm{AF}$.

In 2005, Park et al. (9) reported a SC incidence of $28 \%$ in a medical ICU, although this report comes from a study without coronarography. More recently, Rowell et al. and Oras et al. reported SC incidences of $3.5 \%$ and $5.6 \%$ respectively $(7,8)$. The APACHE II score has been validated as an accurate predictor of clinical outcomes and mortality in critically ill patients (12). Jo et al. (13) identified APACHE II score as significant predictors for in-hospital mortality in critically ill patients with SC, which developed in the medical or surgical ICU. In our study, although there was no significant difference in APACHE II score between the groups, the nonsurvival group had an increasing trend. Previous studies have reported that SC patients were predominantly women, especially postmenopausal women, and an associated stressor was identified in most patients. Emotional triggers were more common than physical triggers (4,14-18). However, the InterTAK Registry has reported that physical stimuli (including fracture, infection, disorders in central nervous system, acute respiratory failure, and stress after operation) were more commonly seen compared to emotional stimuli (including interpersonal conflict, anger anxiety, panic, fear, and grief), at $36.0 \% v s$. $27.7 \%$, respectively. Our study showed that nearly half of the patients were men and that at $88.67 \%$, physical triggers were far more common. Indeed, SC related to physical stress has been found to occur more frequently in male patients than female (4), which provides an explanation for the higher number of male patients in our study. Physical stresstriggered SC was accompanied by more complications, which might be the reason for its higher rate (19). Patients with multiple organ failure were admitted into the ICU. Therefore, compared with emotional factor-triggered SC, patients with physical stress-triggered SC were more likely to be admitted into the ICU. Belcour et al. (20) reported that the prevalence of SC in patients admitted to the ICU for convulsive status epilepticus ranged from $34 \%$ to $62 \%$, age and Simplified Acute Physiology Score II were the risk factors. Sepsis is a frequent cause of admission to ICUs and one of the leading causes of death among hospitalized patients. The most common ICU acquired infections were catheter-related bloodstream infections, pneumonia and abdominal infections. The presence of organ dysfunction and shock, severity of underlying diseases, comorbidities, and a few characteristics of infection were the related risk factors for death in ICU patients with sepsis (21). Doyen et al. (22) reported that sepsis and pulmonary diseases were the most common reasons $(38.50 \%$ and $46.20 \%$, respectively) for SC in the ICU. In our study, sepsis was the most frequent trigger (37.74\%), which was similar to the findings of Doyen's study. We found that respiratory and hemodynamic instability in SC patients in the ICU was increased in comparison with SC patients in a cardiology setting. Based on InterTAK Registry data, Templin et al. (19) demonstrated that the usage of ventilation $(17.3 \%)$ and catecholamines $(12.2 \%)$ was lower and the occurrence of cardiogenic shock $(9.9 \%)$ was decreased among patients with SC admitted to cardiology units. Brinjikji et al. (23) found that $31 \%$ of SC cases were complicated with heart failure. According to their results, respiratory status was affected by the complication of heart failure in only $6.7 \%$ of SC patients. Muratsu et al. (24) reported that $26 \%$ of patients in their study had the complication of heart failure. In our study, $77.36 \%$ and $39.62 \%$ of patients had complications of systolic heart failure and cardiogenic shock, respectively. Norepinephrine was given to $86.79 \%$ of patients, and $79.25 \%$ of patients needed invasive mechanical ventilation. These differences might have resulted from the different target patient groups; the patients transferred to the ICU had relatively severe illnesses.

We explored the 28-day mortality rate of SC patients in the ICU. Our results showed a 28-day mortality rate of $67.50 \%$ in these patients. The mortality rate of SC patients in our study was much higher compared with those in the cardiology unit $(67.50 \%$ in our study vs. $4.1 \%$, respectively) (19). The status of the patients in the ICU was more unstable and patients more frequently presented with multiple organ failure in comparison with SC patients in a cardiology unit, who generally only had heart failure with a much lower mortality rate. There have been no large randomized controlled trials investigating the mortality rate of SC patients in ICUs. One prospective single-center study reported that $30.8 \%$ of SC patients in the ICU died within 30 days (22). Oras et al. (7) reported that the 30-day mortality rate of hemodynamically unstable patients with SC in the ICU was $42 \%$. There are 2 reasons for the higher mortality rate in our ICU than in the literature. First, the tertiary nature of our hospital, with severely ill patients and those directly transferred from other hospitals admitted first, might have contributed to the high mortality rate. Another reason may be that the proportion of patients 
with malignancies in our study was $69.80 \%$, indicating that the basic condition of SC patients in our study was poor. The reason for the high proportion of malignant patients in our study was that our hospital also includes Hebei Cancer Hospital, which is a large comprehensive grade A tertiary hospital focusing on the diagnosis and treatment of cancer. Desai et al. (25) noted that patients suffering from malignancy had an increased risk of developing SC. Additionally, Joy et al. (26) reported that outcomes are significantly worse in patients with SC and malignancy. In this study, further analysis showed that the SOFA score, eGFR $<60 \mathrm{~mL} / \mathrm{min}$ at diagnosis of $\mathrm{SC}$, maximum norepinephrine dose, new-onset $\mathrm{AF}$, and systolic heart failure may have been risk factors of 28-day mortality in SC patients in the ICU. Subsequent analyses found that newonset $\mathrm{AF}$ was an independent risk factor for mortality. As a major cardiac disorder affecting adults, $\mathrm{AF}$ is related to significant morbidity and mortality (27). Indeed, previous investigations have demonstrated that patients in critical condition with new-onset $\mathrm{AF}$ are at elevated risk of inhospital death (28). AF may result in adverse events in SC patients via adverse hemodynamic effects, including atrial contraction loss, rapid ventricular rate, and atrioventricular synchronicity loss, contributing to a decline in cardiac output when the ejection fraction is depressed. Stiermaier et al. (29) showed that left atrium dysfunction was an additional characteristic of acute SC. Disturbances in the left atrium were potentially caused by systolic and diastolic dysfunction in $L V$, which resulted in overloaded pressure and volume in the left atrium and thus contributed to $\mathrm{AF}$ onset during SC. Additionally, SC exerted a direct effect on the left atrium. The autonomic nervous system might have also played an important role. Both parasympathetic and sympathetic tone have been found to participate in $\mathrm{AF}$ pathogenesis (30). Additionally, excess secretion of catecholamine and enhanced activity in sympathetic nerves are widely accepted mechanisms in SC (31). Sympathetically driven episodes of $\mathrm{AF}$ were also deemed conceivable in view of the presumed pathophysiologic connection with catecholamine excess and sympathetic overdrive. Another potential factor was inflammation. In this study, the most common frequent trigger was sepsis. Increased levels of circulating interleukin-6 and -10 have been reported in SC, and systemic inflammation is thought to result in initiating and perpetuating $\mathrm{AF}$ (32-35).

The SOFA score at diagnosis of SC was the next independent risk factor for 28-day mortality in this study, and is considered an excellent assessment for predicting short-term mortality in sepsis and other life-threatening conditions (36). In our study, SOFA score was considered an independent risk factor for 28-day mortality, and eGFR $<60 \mathrm{~mL} / \mathrm{min}$ at diagnosis of SC was another independent risk factor for 28-day mortality. After analysis of the results, we proposed the following reason: SC is an increasingly recognized form of acute heart failure. Notably, decreased cardiac output due to worsening LV function could result in injured renal function via underperfusion, the sympathetic nervous system, and the activated reninangiotensin-aldosterone axis (37). One systematic review involving observational studies reported that decreased eGFR was related to an elevated risk of coronary heart disease (38). A meta-analysis found that low eGFR was related to cardiovascular and all-cause mortality in the general population (39). El-Battrawy et al. (40) reported eGFR $<60 \mathrm{~mL} / \mathrm{min}$ as an independent predictor of adverse outcomes in SC.

\section{Limitations}

Our study had some limitations. First, our work was a retrospective, single-center, observational study. The number of patients included was relatively low. Second, there were problems in acquiring certain data, including C-reactive protein, the duration time of $\mathrm{AF}$, and the dynamic changes in cardiac function parameters. Thus, further prospective multicenter research is required on this topic.

\section{Conclusions}

Male SC patients with physical stress were relatively more common in the ICU than in the cardiology unit. The 28 -day mortality rate was $67.50 \%$. New-onset AF was common in SC patients in the ICU. New-onset AF, SOFA score at diagnosis of SC, and eGFR $<60 \mathrm{~mL} / \mathrm{min}$ at diagnosis of SC may have influenced patients' shortterm prognosis. Positively addressing new-onset $\mathrm{AF}$ in $\mathrm{SC}$ patients in the ICU may contribute to the improvement of patient outcomes.

\section{Acknowledgments}

We thank the patients for their cooperation during the treatment process.

Funding: This study was supported by the Public Health Foundation of Hebei Province of China (20160156) and the 
Department of Science and Technology of Hebei Province of China (20277707D).

\section{Footnote}

Reporting Checklist: The authors have completed the STROBE reporting checklist. Available at https://dx.doi. org/10.21037/apm-21-3223

Data Sharing Statement: Available at https://dx.doi. org/10.21037/apm-21-3223

Conflicts of Interest: All authors have completed the ICMJE uniform disclosure form (available at https://dx.doi. org/10.21037/apm-21-3223). The authors have no conflicts of interest to declare.

Ethical Statement: The authors are accountable for all aspects of the work in ensuring that questions related to the accuracy or integrity of any part of the work are appropriately investigated and resolved. All procedures performed in this study involving human participants were in accordance with the Declaration of Helsinki (as revised in 2013). The study was approved by Ethics Committee of The Fourth Hospital of Hebei Medical University (No. 2021KS045). Individual consent for this retrospective analysis was waived.

Open Access Statement: This is an Open Access article distributed in accordance with the Creative Commons Attribution-NonCommercial-NoDerivs 4.0 International License (CC BY-NC-ND 4.0), which permits the noncommercial replication and distribution of the article with the strict proviso that no changes or edits are made and the original work is properly cited (including links to both the formal publication through the relevant DOI and the license). See: https://creativecommons.org/licenses/by-nc-nd/4.0/.

\section{References}

1. Akashi YJ, Goldstein DS, Barbaro G, et al. Takotsubo cardiomyopathy: a new form of acute, reversible heart failure. Circulation 2008;118:2754-62.

2. Zhang L, Piña IL. Stress-Induced Cardiomyopathy. Heart Fail Clin 2019;15:41-53.

3. Citro R, Okura H, Ghadri JR, et al. Multimodality imaging in takotsubo syndrome: a joint consensus document of the European Association of Cardiovascular Imaging (EACVI) and the Japanese Society of Echocardiography (JSE). Eur Heart J Cardiovasc Imaging 2020;21:1184-207.

4. Lyon AR, Bossone E, Schneider B, et al. Current state of knowledge on Takotsubo syndrome: a Position Statement from the Taskforce on Takotsubo Syndrome of the Heart Failure Association of the European Society of Cardiology. Eur J Heart Fail 2016;18:8-27.

5. Rawish E, Stiermaier T, Santoro F, et al. Current Knowledge and Future Challenges in Takotsubo Syndrome: Part 1-Pathophysiology and Diagnosis. J Clin Med 2021;10:479.

6. Champion S, Belcour D, Vandroux D, et al. Stress (Takotsubo) cardiomyopathy in critically-ill patients. Eur Heart J Acute Cardiovasc Care 2015;4:189-96.

7. Oras J, Lundgren J, Redfors B, et al. Takotsubo syndrome in hemodynamically unstable patients admitted to the intensive care unit - a retrospective study. Acta Anaesthesiol Scand 2017;61:914-24.

8. Rowell AC, Stedman WG, Janin PF, et al. Silent left ventricular apical ballooning and Takotsubo cardiomyopathy in an Australian intensive care unit. ESC Heart Fail 2019;6:1262-5.

9. Park JH, Kang SJ, Song JK, et al. Left ventricular apical ballooning due to severe physical stress in patients admitted to the medical ICU. Chest 2005;128:296-302.

10. Ghadri JR, Wittstein IS, Prasad A, et al. International Expert Consensus Document on Takotsubo Syndrome (Part I): Clinical Characteristics, Diagnostic Criteria, and Pathophysiology. Eur Heart J 2018;39:2032-46.

11. Levey AS, Bosch JP, Lewis JB, et al. A more accurate method to estimate glomerular filtration rate from serum creatinine: a new prediction equation. Modification of Diet in Renal Disease Study Group. Ann Intern Med 1999;130:461-70.

12. Wong DT, Crofts SL, Gomez M, et al. Evaluation of predictive ability of APACHE II system and hospital outcome in Canadian intensive care unit patients. Crit Care Med 1995;23:1177-83.

13. Jo YY, Chang HJ, Na S, et al. Predictors of mortality in patients with stress-induced cardiomyopathy developed during critical care. J Crit Care 2013;28:618-24.

14. Looi JL, Verryt T, McLeod P, et al. A comparison of the clinical features and outcomes of Takotsubo syndrome across five metropolitan hospitals in New Zealand. N Z Med J 2020;133:73-82.

15. Pelliccia F, Kaski JC, Crea F, et al. Pathophysiology of Takotsubo Syndrome. Circulation 2017;135:2426-41.

16. Sattar Y, Siew KSW, Connerney M, et al. Management of 
Takotsubo Syndrome: A Comprehensive Review. Cureus 2020;12:e6556.

17. Dawson DK. Acute stress-induced (takotsubo) cardiomyopathy. Heart 2018;104:96-102.

18. Imori Y, Kato K, Cammann VL, et al. Ethnic comparison in takotsubo syndrome: novel insights from the International Takotsubo Registry. Clin Res Cardiol 2021. doi: 10.1007/s00392-021-01857-4.

19. Templin C, Ghadri JR, Diekmann J, et al. Clinical Features and Outcomes of Takotsubo (Stress) Cardiomyopathy. N Engl J Med 2015;373:929-38.

20. Belcour D, Jabot J, Grard B, et al. Prevalence and Risk Factors of Stress Cardiomyopathy After Convulsive Status Epilepticus in ICU Patients. Crit Care Med 2015;43:2164-70.

21. Alberti C, Brun-Buisson C, Goodman SV, et al. Influence of systemic inflammatory response syndrome and sepsis on outcome of critically ill infected patients. Am J Respir Crit Care Med 2003;168:77-84.

22. Doyen D, Moschietto S, Squara F, et al. Incidence, clinical features and outcome of Takotsubo syndrome in the intensive care unit. Arch Cardiovasc Dis 2020;113:176-88.

23. Brinjikji W, El-Sayed AM, Salka S. In-hospital mortality among patients with takotsubo cardiomyopathy: a study of the National Inpatient Sample 2008 to 2009. Am Heart J 2012;164:215-21.

24. Muratsu A, Muroya T, Kuwagata Y. Takotsubo cardiomyopathy in the intensive care unit. Acute Med Surg 2019;6:152-7.

25. Desai A, Noor A, Joshi S, et al. Takotsubo cardiomyopathy in cancer patients. Cardiooncology 2019;5:7.

26. Joy PS, Guddati AK, Shapira I. Outcomes of Takotsubo cardiomyopathy in hospitalized cancer patients. J Cancer Res Clin Oncol 2018;144:1539-45.

27. Nso N, Bookani KR, Metzl M, et al. Role of inflammation in atrial fibrillation: A comprehensive review of current knowledge. J Arrhythm 2021;37:1-10.

28. Walkey AJ, Wiener RS, Ghobrial JM, et al. Incident stroke and mortality associated with new-onset atrial fibrillation in patients hospitalized with severe sepsis. JAMA 2011;306:2248-54.

29. Stiermaier T, Graf T, Möller C, et al. Transient left atrial dysfunction is a feature of Takotsubo syndrome. $\mathrm{J}$ Cardiovasc Magn Reson 2017;19:15.

30. Kusayama T, Wan J, Yuan Y, et al. Neural Mechanisms and Therapeutic Opportunities for Atrial Fibrillation. Methodist Debakey Cardiovasc J 2021;17:43-7.
31. Kakturskiy LV, Mikhaleva LM, Mishnev OD, et al. Takotsubo syndrome (stress-induced cardiomyopathy). Arkh Patol 2021;83:5-11.

32. Santoro F, Tarantino N, Ferraretti A, et al. Serum interleukin 6 and 10 levels in Takotsubo cardiomyopathy: Increased admission levels may predict adverse events at follow-up. Atherosclerosis 2016;254:28-34.

33. Phillips KP. Role of Inflammation in Initiation and Perpetuation of Atrial Fibrillation: A Systematic Review of the Published Data. J Atr Fibrillation 2013;6:935.

34. Scally C, Abbas H, Ahearn T, et al. Myocardial and Systemic Inflammation in Acute StressInduced (Takotsubo) Cardiomyopathy. Circulation 2019;139:1581-92.

35. Yalta K, Yetkin E, Yalta T. Systemic inflammation in patients with Takotsubo syndrome: a review of mechanistic and clinical implications. Monaldi Arch Chest Dis 2021.

36. Raith EP, Udy AA, Bailey M, et al. Prognostic Accuracy of the SOFA Score, SIRS Criteria, and qSOFA Score for In-Hospital Mortality Among Adults With Suspected Infection Admitted to the Intensive Care Unit. JAMA 2017;317:290-300.

37. Rangaswami J, Bhalla V, Blair JEA, et al. Cardiorenal Syndrome: Classification, Pathophysiology, Diagnosis, and Treatment Strategies: A Scientific Statement From the American Heart Association. Circulation 2019;139:e840-78.

38. Di Angelantonio E, Danesh J, Eiriksdottir G, et al. Renal function and risk of coronary heart disease in general populations: new prospective study and systematic review. PLoS Med 2007;4:e270.

39. Chronic Kidney Disease Prognosis Consortium; Matsushita K, van der Velde M, et al. Association of estimated glomerular filtration rate and albuminuria with all-cause and cardiovascular mortality in general population cohorts: a collaborative meta-analysis. Lancet 2010;375:2073-81.

40. El-Battrawy I, Lang S, Ansari U, et al. Prevalence of malignant arrhythmia and sudden cardiac death in takotsubo syndrome and its management. Europace 2018;20:843-50.

Cite this article as: Yao T, Chen Y, Ma J, Hu Z. Clinical characteristics and risk factors for death in patients with stress cardiomyopathy in the ICU. Ann Palliat Med 2021;10(12):1242012430. doi: 10.21037/apm-21-3223 